\title{
KAPASITAS PEREMPUAN TANI UNTUK MEWUJUDKAN KETAHANAN PANGAN RUMAH TANGGA DALAM MENGHADAPI ERA GLOBALISASI DI KOTA PEKANBARU
}

\author{
Penti Suryani $\left.{ }^{*}\right)$, dan Ahmad Darmawi2) \\ 1Ketua Laboratorium Sosial Ekonomi Fakultas Pertanian dan Peternakan UIN Suska Riau \\ 2Staf Pengajar Fakultas Pertanian dan Peternakan UIN Suska Riau \\ *)Penulis korespondensi: suryani_penti@yahoo.com
}

\begin{abstract}
This study aims to determine 1) the condition of household food security, 2) the factors that affect the capacity of women farmers in food consumption in order to achieve food security at the household level, 3) the factors that affect spending foodstuffs on the level households and 4) the capacity of women farmers to achieve household food security in the era of globalization in the city of Pekanbaru. This study uses a crosssectional study design, located in four districts in the city of Pekanbaru namely District Tampan, District Marpoyan Damai, District and Sub-district Rumbai and Rumbai Pesisir. Primary data was collected using a questionnaire which was distributed to 100 respondents of women farmers selected by simple random sampling. Factors that affect the capacity of women farmers in achieving food security household level are: income, education and nutrition knowledge of women farmers. Factors that affect spending foodstuffs at the household level women farmers in the city of Pekanbaru is the price of rice, household income, number of household members and the level of education. Capacity of women farmers in food processing is still at the low level. Threats of globalization on food security in Pekanbaru city can be resolved by the farmer community empowerment program. Empowerment of women farmers not only to protect the rice trade, but also to uplift the lives of women farmers through programs that improve local agricultural businesses.
\end{abstract}

Kata Kunci: perempuan tani, ketahanan pangan dan globalisasi

\section{PENDAHULUAN}

Pangan adalah kebutuhan dasar manusia yang paling utama. Dalam hal ini, pemenuhan pangan merupakan bagian dari hak asasi individu. Kualitas dan kuantitas bahan pangan akan berpengaruh terhadap eksistensi dan ketahanan hidup setiap individu. Tersedianya pangan yang cukup, aman, bermutu, bergizi dan halal merupakan prasyarat utama yang harus dipenuhi di setiap rumahtangga dalam upaya mewujudkan insan yang berharkat dan bermartabat serta sumberdaya manusia yang berkualitas (Elizabeth, 2007).
Mengingat pentingnya memenuhi kecukupan pangan, maka setiap negara akan mendahulukan pembangunan ketahanan pangannya sebagai fondasi bagi pembangunan sektor-sektor lainnya. Dengan demikian, ketahanan pangan merupakan hal yang sangat penting dan strategis. Komitmen Indonesia untuk mewujudkan pembangunan ketahanan pangan ditegaskan dalam Undang-Undang Ketahanan Pangan Nomor 7 Tahun 1996 tentang Pangan dan Peraturan Pemerintah Nomor 68 Tahun 2002 tentang Ketahanan Pangan (BBKP, 2003). Ketahanan pangan didefenisikan sebagai 
tersedianya pangan dalam jumlah dan kualitas yang cukup, terdistribusi dengan harga yang terjangkau dan aman dikonsumsi bagi masyarakat untuk dapat melakukan aktivitas sehari-hari sepanjang waktu. Berdasarkan defenisi tersebut, maka fokus ketahanan pangan tidak hanya cukup pada penyediaan dan konsumsi pangan sampai tingkat global, nasional maupun regional tetapi juga harus sampai pada tingkat rumah tangga dan individu dalam memenuhi kebutuhan gizinya (Ariani, 2005).

Di dalam rumah tangga, perempuan adalah aktor kunci dalam pencapaian ketahanan pangan rumah tangganya.Salah satu alasannya adalah ketahanan pangan merupakan bagian dari peranan reproduktif mereka. Kenyataan bahwa fungsi rumah tangga sebagai unit konsumsi, peranan reproduktif perempuan berkembang pada ketahanan pangan dan nutrisi rumah tangganya secara keseluruhan dan tidak terbatas hanya pada anak-anak mereka. Produksi ketahanan pangan dan nutrisi rumah tangga terdiri dari beberapa aktivitas yang saling terkait, yaitu budidaya tanaman pangan, pengadaan pangan, pengumpulan dan penukaran, persiapan dan pengolahan pangan, dan akhirnya distribusi pangan.Hampir semua aktivitas ini merupakan tugas perempuan.Mendapatkan atau mengakses sumberdaya yang memungkinkan melaksanakan aktivitas tersebut juga merupakan tugas perempuan.
Namun demikian kendala lingkungan dan sosial yang menghambat perempuan dalam mengakses cukup sumberdaya untuk melaksanakan aktivitas-aktivitas tersebut dalam sistem pangan menimbulkan permasalahan serius bagi perempuan untuk melaksanakan tanggung jawab reproduktif mereka dan sering berakibat pada buruknya kondisi nutrisi anak (Aprodev cit Sukiyono, 2008).

Globalisasi merupakan sebuah kenyataan yang tidak bisa dihindari oleh setiap bangsa, sehingga mau tidak mau, suka atau tidak suka, siap atau tidak siap, setiap bangsa harus mengikuti arus tersebut. Globalisasi diwarnai oleh ekspansi pasar yang dalam bentuk kongkret menjelma dalam berbagai penyelenggaraan pasar-pasar bersama regional dalam pertarungan bebas di pasaran internasional. Selain itu untuk mengembalikan makanan lokal agar diterima oleh masyarakat, khususnya dalam bersaing dengan produk asing, diperlukan diversifikasi pangan. Hal ini dapat dilakukan dengan membuat aneka ragam makanan dengan bahan dasar seperti jagung, umbiumbian, sagu dan sosialisasi makanan non beras perlu digencarkan untuk mengantisipasi kekurangan pangan nasional.

Upaya lain untuk mengembangkan ketahanan pangan adalah melalui diversifikasi pangan baik dari sisi jenis pangan maupun tampilannya dengan bahan dasar hasil pertanian lokal seprti jagung, ubi, 
singkong dan lain-lain. Hal ini akan membawa minat konsumsi ke pangan lokal meningkat. Dan untuk memperkenalkan potensi daerah dalam hal pangan, perlu penyajian yang menarik karena untuk mengimbangi produk impor.Dalam era globalisasi ini masyarakat tidak bisa lagi diajak makan jagung dan ubi rebus secara langsung. Bentuk sajian makanan berbahan baku singkong dan jagung harus sesuai dengan gaya kosmopolitan. Untuk itu ke depan perlu dikembangkan makanan berbasis tepung seperti ubi kayu, jagung dan sagu sehingga mudah disimpan dan diolah (Suhartini, 2004).

Dampak dari kebijakan pangan masa orde baru adalah konstruksi sosiologis masyarakat yang menunjukkan bahwa makan nasi lebih elit dibanding makan singkong. Oleh karena itu terkait dengan diversifikasi maka perlu menggeser proporsi konsumsi padi-padian dari sumber karbohidrat ke jenis bahan pangan lain seperti umbi-umbian, jagung dan lain-lain (Hariyadi, 2006).

Berdasarkan uraian di atas, maka penelitian ini akan mengkaji: (1) Kondisi ketahanan pangan rumah tangga perempuan tani di Kota Pekanbaru; (2) Faktor-faktor yang mempengaruhi peran perempuan tani dalam konsumsi bahan pangan guna mewujudkan ketahanan pangan pada tingkat rumah tangga di Kota Pekanbaru; (3) Mengetahui faktor-faktor yang mempengaruhi pengeluaran bahan-bahan pangan pada tingkat rumah tangga dan 4) Mengetahui kapasitas perempuan tani untuk mewujudkan ketahanan pangan rumah tangga dalam menghadapi era globalisasi di Kota Pekanbaru.

Penelitian ini mengambil lokasi penelitian di Kota Pekanbaru, lokasi yang diambil merupakan sentra agribisnis sayuran berdaun lebar dan perempuan tani sebagai pelaku utama dalam kegiatan agribisnis sayuran tersebut.

\section{METODOLOGI PENELITIAN}

\section{Lokasi Penelitian}

Penelitian dilakukan pada 4 kecamatan di Kota Pekanbaru yakni Kecamatan Tampan, Kecamatan Marpoyan Damai, Kecamatan Rumbai dan Kecamatan Rumbai Pesisir. Pengambilan sampel dilakukan dengan metode simple random sampling.Jumlah responden penelitian adalah sebanyak 100 rumah tangga perempuan tani. Responden yanag dimaksud dalam penelitian ini adalah seseorang yang berjenis kelamin perempuan dan sudah menikah; menjadi kepala keluarga dan atau anggota keluarga; berumur di atas 17 tahun, termasuk kategori keluarga miskin dan perempuan tani yang bergabung dalam kelompok perempuan tani atau kelompok PKK terkait aktivitasnya dalam pengolahan tampilan bahan pangan lokal menjadi tampilan yang kosmopolitan. 


\section{Metode}

Kondisi ketahanan pangan rumah tangga perempuan tani dapat diketahui dengan menggunakan derajat ketahanan pangan. Indikator ini diestimasi dengan cara menghitung jumlah jenis pangan atau kelompok pangan yang dikonsumsi oleh kelompok rumah tangga dimana survey dilakukan. Smith dan Subandono (2007) cit Amirian (2008). mengelompokkan pangan menjadi 7 kelompok atau jenis. Ketujuh kelompok pangan itu adalah: (biji-bijian, akar-akaran, dan umbi-umbian; (2) kacangkacangan; (3) produk ternak; (4) daging, ikan dan telur; (5) minyak dan lemak; (6) buahbuahan; dan (7) sayur-sayuran. Swindale dan Bilinsky (2007) cit Amirian (2008) membagi derajat ketahanan pangan menjadi tiga, yaitu: tinggi, bila konsumsi pangan $>6$; sedang bila konsumsi pangan 4,5-6; dan rendah bila konsumsi pangan $<4$, sedangkan derajat ketahanan pangan menjadi dua, yaitu rawan pangan, bila konsumsi pangan $<5,6$ dan tahan pangan bila konsumsi pangan $\geq$ 5,6 .

Pengkategorian variabel penelitian dapat dilihat pada Tabel 1 berikut ini.

Tabel 1. Pengkategorian Variabel Penelitian

\begin{tabular}{|c|c|c|c|}
\hline No. & Variabel & Kategori & Sumber \\
\hline & $\begin{array}{l}\text { Umur KRT, Ibu dan } \\
\text { ART }\end{array}$ & $\begin{array}{l}\text { Lansia: } \geq 60 \text { tahun } \\
\text { Dewasa madya: } 40-59 \text { tahun } \\
\text { Dewasa awal: } 20-39 \text { tahun } \\
\text { Remaja: } 12-19 \text { tahun } \\
\text { AUS: } 6-11 \text { tahun } \\
\text { Balita: } 25-60 \text { bulan } \\
\text { Bayi:0-24 bulan }\end{array}$ & Hurlock (1980) \\
\hline 2. & $\begin{array}{l}\text { Pendidikan KRT, Ibu } \\
\text { dan ART }\end{array}$ & $\begin{array}{l}\text { TS: } 0 \text { tahun } \\
\text { SD: } 6 \text { tahun } \\
\text { SMP: } 9 \text { tahun } \\
\text { SMA: } 12 \text { tahun } \\
\text { PT: } 16 \text { tahun }\end{array}$ & - \\
\hline 3. & Ukuran rumah tangga & $\begin{array}{l}\text { Rumah tangga kecil: } \leq 4 \text { orang } \\
\text { Rumah tangga sedang: } 5 \text { - } 6 \text { orang } \\
\text { Rumah tangga besar: } \geq 7 \text { orang }\end{array}$ & BKKBN (1998) \\
\hline 4. & Kepemilikan lahan & $\begin{array}{l}0 \mathrm{~m}^{2} \\
<5.000 \mathrm{~m}^{2} \\
5.000-10.000 \mathrm{~m}^{2} \\
>10.000 \mathrm{~m}^{2}\end{array}$ & - \\
\hline 5. & Pengeluaran & $\begin{array}{l}\text { Miskin: } \leq \text { GK } \\
\text { Tidak miskin: > GK }\end{array}$ & BPS (2007) \\
\hline 6. & Pengetahuan Gizi & $\begin{array}{l}\text { Rendah: } \leq 5 \\
\text { Sedang: } 6-7 \\
\text { Tinggi: } \geq 8\end{array}$ & $\begin{array}{l}\text { Rumus Interval } \\
\text { Slamet (1998) }\end{array}$ \\
\hline 7. & $\begin{array}{l}\text { Tingkat Konsumsi: } \\
\text { Energi dan Protein }\end{array}$ & $\begin{array}{l}\text { Defisit berat: }<70 \% \\
\text { Defisit sedang: } 70-79 \%\end{array}$ & Depkes (1996) \\
\hline
\end{tabular}


Defisit berat: $80-89 \%$

Normal: $90-119 \%$

Lebih: $\geq 120 \%$

Vitamin dan mineral

Defisit: $\leq 50 \%$

Cukup: $>50 \%$

Depkes (2003)

Rawan pangan berat: TKE $<70 \%$

Rawan pangan sedang: TKE $70-80 \%$

FAO (2003)

8. Ketahanan pangan

Rawan pangan ringan: TKE $81-90 \%$

Tahan pangan: TKE $>90 \%$

Untuk mengetahui peran perempuan tani dalam konsumsi bahan pangan pada tingkat rumah tangga di Kota Pekanbaru digunakan model analisis sebagai berikut:

$$
Y i=f(I h, \text { If, Af, Ef, S, U,DI) }
$$

Keterangan:

$\mathrm{Yi}=$ Konsumsi bahan pangan pada tingkat rumah tangga ke - i (RP/kapita/tahun)

$$
\begin{aligned}
& \mathrm{i} \quad=1,2, \ldots, \mathrm{n} \\
& \text { Ih }=\text { Pendapatan rumah tangga } \\
& \text { (Rp/tahun) } \\
& \text { If }=\text { Pendapatan perempuan tani } \\
& \text { (Rp/tahun) } \\
& \text { Ef } \quad=\text { Pendidikan perempuan (tahun) } \\
& \mathrm{S} \quad=\text { Jumlah anggota keluarga (jiwa) } \\
& \mathrm{U} \quad=\text { Umur Perempuan Tani } \\
& \text { Pg } \quad=\text { Pengetahuan Gizi Perempuan Tani }
\end{aligned}
$$

Selanjutnya untuk mengetahui faktorfaktor yang mempengaruhi pengeluaran bahan pangan pokok pada tingkat rumah tangga di Kota Pekanbaru digunakan model sebagai berikut:

$$
Y i=f(P h, P h i, I h, S, E f)
$$

Keterangan:
Yi = Pengeluaran bahan pangan pada tingkat rumah tangga ke - i (RP/kapita/tahun)

$\mathrm{Ph}=$ Harga Beras

PHi = Harga bahan pangan lainnya ke i $(\mathrm{i}$ $=1,2, . ., \mathrm{n})(\mathrm{Rp} /$ tahun $)$

Ih = Pendapatan rumah tangga $(\mathrm{Rp} / \mathrm{th})$

Ef = Pendidikan Perempuan Tani

Untuk melihat faktor-faktor yang berhubungan dengan ketersediaan energi/kap/hari (cerminan kapasitas perempuan tani dalam mewujudkan ketahanan pangan dan hubungannya dengan ancaman globalisasi) dianalisis dengan uji Korelasi Spearmen (Amirian, 2008).

\section{HASIL DAN PEMBAHASAN}

\section{Profil Responden}

Informasi tentang karakteristik rumah tangga sangat penting untuk memberikan gambaran mengenai kondisi aktul rumah tangga sebelum mengkaitkan dengan derajat ketahanan pangan rumah tangga.Karakteristik sosial ekonomi rumah tangga perempuan tani di Kota Pekanbaru disajikan pada tabel berikut ini. 
$\underline{\text { Umur }}$

Klasifikasi umur kepala rumah tangga (KRT) dibagi menjadi tiga kelompok umur berdasarkan Hurlock (1980), yaitu dewasa awal (18-39), dewasa madya (40-59 tahun), dan lansia ( $\geq 60$ tahun). Klasifikasi umur kepala rumah tangga dapat dilihat pada Tabel

Tabel 2. Klasifikasi Umur Kepala Rumah Tangga

\begin{tabular}{ccccccccccc}
\hline $\begin{array}{l}\text { Kelompok } \\
\text { Umur }\end{array}$ & \multicolumn{2}{c}{ Tampan } & \multicolumn{2}{c}{$\begin{array}{c}\text { Marpoyan } \\
\text { Damai }\end{array}$} & \multicolumn{2}{c}{ Rumbai } & \multicolumn{2}{c}{ Rumbai } \\
Pesisir & \multicolumn{3}{c}{ Total } \\
& $\mathrm{n}$ & $\%$ & $\mathrm{n}$ & $\%$ & $\mathrm{n}$ & $\%$ & $\mathrm{n}$ & $\%$ & $\mathrm{n}$ & $\%$ \\
\hline 18-39 tahun & 13 & 56.5 & 12 & 30.8 & 4 & 22.2 & 5 & 25.0 & 36 & 36.0 \\
40-59 tahun & 7 & 30.4 & 20 & 51.2 & 12 & 66.6 & 10 & 50.0 & 47 & 46.0 \\
$\geq 60$ tahun & 3 & 13.1 & 7 & 18 & 1 & 11.2 & 6 & 30.0 & 17 & 18.0 \\
Jumlah & 23 & 100.0 & 39 & 100.0 & 17 & 100.0 & 21 & 100.0 & 100 & 100.0 \\
\hline
\end{tabular}

Dari keempat kecamatan tersebut terlihat bahwa sebaran umur kepala rumahtangga terbesar (46.0 persen) berada pada kelompok umur dewasa madya (40-59 tahun), selanjutnya sebanyak 36.0 persen merupakan KRT dengan kelompok umur dewasa awal, dan terakhir 18.0 persen KRT tergolong kelompok umur lansia $(\geq 60$ tahun).

Tabel 3. Sebaran Rumahtangga Berdasarkan Ketahanan Pangan dan Umur KRT

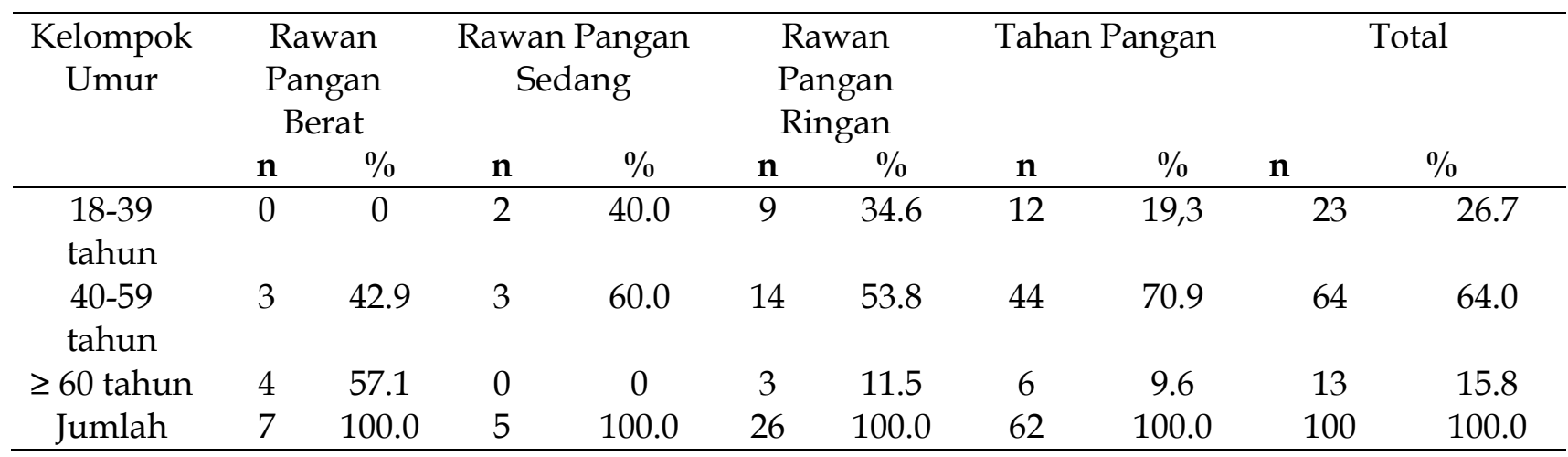

Sebaran ketahanan pangan rumahtangga berdasarkan umur KRT dapat dilihat pada Tabel 3. Sebaran rumahtangga tahan pangan berdasarkan kelompok umur KRT menunjukkan bahwa umur KRT pada rumah tangga tahan pangan sebagian besar
(70.9 \%) termasuk kelompok umur dewasa madya (40-59 tahun), sisanya masing-masing sebanyak 19.3 persen dan 9.6 persen termasuk kelompok umur dewasa awal dan lansia. Klasisfikasi umur ibu rumahtangga (IRT) dibagi menjadi tiga kelompok umur, 
yaitu dewasa awal (18-39 tahun), dewasa madya (40-59 tahun), dan lansia ( $\geq 60$
tahun).Klasifikasi umur IRT dapat dilihat pada

Tabel
4.

Tabel 4. Klasifikasi Umur Ibu Rumah Tangga

\begin{tabular}{|c|c|c|c|c|c|c|c|c|c|c|}
\hline \multirow[t]{2}{*}{$\begin{array}{c}\text { Kelompok } \\
\text { Umur }\end{array}$} & \multicolumn{2}{|c|}{ Tampan } & \multicolumn{2}{|c|}{$\begin{array}{c}\text { Marpoyan } \\
\text { Damai }\end{array}$} & \multicolumn{2}{|c|}{ Rumbai } & \multicolumn{2}{|c|}{$\begin{array}{c}\text { Rumbai } \\
\text { Pesisir }\end{array}$} & \multicolumn{2}{|c|}{ Total } \\
\hline & $\mathbf{n}$ & $\%$ & $\mathbf{n}$ & $\%$ & $\mathbf{n}$ & $\%$ & $\mathrm{n}$ & $\%$ & $\mathbf{n}$ & $\%$ \\
\hline 18-39 tahun & 12 & 52.2 & 12 & 30.7 & 6 & 33.3 & 4 & 20.0 & 34 & 33.7 \\
\hline 40-59 tahun & 9 & 39.1 & 22 & 56,4 & 10 & 55.5 & 12 & 60.0 & 53 & 52.5 \\
\hline$\geq 60$ tahun & 1 & 8.7 & 5 & 12.9 & 2 & 11.2 & 4 & 20.0 & 12 & 12.8 \\
\hline Jumlah & 23 & 100.0 & 39 & 100.0 & 18 & 100.0 & 20 & 100.0 & 100 & 100.0 \\
\hline
\end{tabular}

Dilihat berdasarkan tabel klasifikasi umur IRT di atas, terlihat bahwa distribusi umur perempuan tani terbanyak $(52.5 \%)$ berada pada kelompok umur dewasa madya (40-59 tahun), sebaran berikutnya 33.7 persen berada pada kelompok umur dewasa awal (18-39 tahun), dan terakhir 12.8 persen berada pada kelompok umur lansia $(\geq 60$ tahun). Dengan demikian dapat Tabel 5. Klasifikasi Pekerjaan KRT

\begin{tabular}{|c|c|c|c|c|c|c|c|c|c|c|}
\hline \multirow[t]{2}{*}{ Jenis Pekerjaan } & \multicolumn{2}{|c|}{ Tampan } & \multicolumn{2}{|c|}{$\begin{array}{c}\text { Marpoyan } \\
\text { Damai }\end{array}$} & \multicolumn{2}{|c|}{ Rumbai } & \multicolumn{2}{|c|}{$\begin{array}{c}\text { Rumbai } \\
\text { Pesisir }\end{array}$} & \multicolumn{2}{|c|}{ Total } \\
\hline & $\mathbf{n}$ & $\%$ & $\mathbf{n}$ & $\%$ & $\mathbf{n}$ & $\%$ & $\mathbf{n}$ & $\%$ & $\mathbf{n}$ & $\%$ \\
\hline \multicolumn{11}{|l|}{ Pekerjaan Utama } \\
\hline \multicolumn{10}{|c|}{ Pekerjaan Tambahan } & 100 \\
\hline Tidak ada & 16 & 69.5 & 33 & 84.6 & 13 & 72.2 & 18 & 85.7 & 80 & 79.4 \\
\hline Pedagang & 0 & 0 & 3 & 7.6 & 0 & 0 & 0 & 0 & 3 & 2.9 \\
\hline Buruh & 3 & 13.0 & 3 & 7.6 & 5 & 27.7 & 3 & 14.2 & 14 & 13.9 \\
\hline Wiraswasta & 1 & 4.3 & 0 & 0 & 0 & 0 & 0 & 0 & 1 & 0.9 \\
\hline Pegawai & 2 & 8.6 & 0 & 0 & 0 & 0 & 0 & 0 & 2 & 8.6 \\
\hline Jumlah & 23 & 100 & 39 & 100 & 18 & 100 & 21 & 100 & 100 & 100 \\
\hline
\end{tabular}


Dari Tabel 5 dapat dilihat bahwa pekerjaan utama kepala rumahtangga di keempat kecamatan tersebut adalah petani.Sementara untuk pekerjaan tambahan, di Kecamatan Tampan 69.5 persen kepala keluarga tersebut tidak memiliki pekerjaan tambahan dan hanya tergantung pada pekerjaan utama sebagai petani.

\section{Kontrol Keuangan}

Menurut Sajogyo (1983) tingkat keputusan dihubungkan dengan pengeluaran dalam kebutuhan pokok yang terdiri dari: (1) makanan (biaya hidup, jenis atau menu makanan, distribusi), perumahan (pembelian dan perbaikan), pakaian, pendidikan, kesehatan, dan perabot Tabel 6. Sebaran Rumahtangga Menurut Kontrol Keuangan di Empat Kecamatan rumah tangga. Sedangkan untuk jenis keputusan rumahtangga, dikelompokkan dalam lima tingkatan yaitu: (1) keputusan dibuat oleh istri seorang diri tanpa melibatkan suami, (2) keputusan dibuat bersama oleh suami-istri, tetapi dengan pengaruh yang lebih besar dari istri, (3) keputusan dibuat bersama dan senilai oleh suami istri (dengan tidak ada tanda-tanda bahwa salah satu mempunyai pengaruh yang relative lebih besar), (4) keputusan dibuat bersama oleh suami istri, tetapi dengan pengaruh yang lebih besar dari suami, (5) keputusan dibuat oleh suami seorang diri tanpa melibatkan isteri.

\begin{tabular}{ccccc}
\hline $\begin{array}{c}\text { Kecamatan } \\
\text { Jenis Keputusan }\end{array}$ & $\begin{array}{c}\text { Tampan } \\
\text { Istri Dominan }\end{array}$ & $\begin{array}{c}\text { Marpoyan Damai } \\
\text { Istri Dominan }\end{array}$ & $\begin{array}{c}\text { Rumbai } \\
\text { Istri Dominan }\end{array}$ & $\begin{array}{c}\text { Rumbai Pesisir } \\
\text { Istri Dominan }\end{array}$ \\
\hline Makanan & 28 & $\mathbf{( \% )}$ & $\mathbf{( \% )}$ & $\mathbf{( \% )}$ \\
Pendidikan & 22 & 43.1 & 28 & 20 \\
Kesehatan & 20 & 39.2 & 22 & 20 \\
Perumahan & 28 & 58.8 & 20 & 28 \\
Pakaian & 34 & 49 & 30 & 32 \\
Peralatan RT & 22 & 58.8 & 34 & 18 \\
Rekreasi & 22 & 66.7 & 20 & 22 \\
Tabungan & 18 & 60.8 & 22 & 18 \\
Keseluruhan & 20 & 60.8 & 18 & 20 \\
\hline
\end{tabular}

Terlihat dari hasil penelitian bahwa perempuan tani di Kecamatan Marpoyan
Damai yang merupakan sentra agribisnis sayuran berdaun lebar, mulai dari 
keputusan untuk konsumsi makanan hingga

dominan

peranannya.

ke tabungan keluarga, perempuan jauh lebih

Tabel 7. Klasifikasi Ukuran Rumah Tangga Perempuan Tani

\begin{tabular}{|c|c|c|c|c|c|c|c|c|c|c|}
\hline \multirow{2}{*}{$\begin{array}{c}\text { Ukuran } \\
\text { Rumahtangga }\end{array}$} & \multirow{2}{*}{\multicolumn{2}{|c|}{ Tampan }} & \multirow{2}{*}{\multicolumn{2}{|c|}{$\begin{array}{c}\text { Marpoyan } \\
\text { Damai }\end{array}$}} & \multirow{2}{*}{\multicolumn{2}{|c|}{ Rumbai }} & \multirow{2}{*}{\multicolumn{2}{|c|}{$\begin{array}{l}\text { Rumbai } \\
\text { Pesisir }\end{array}$}} & \multicolumn{2}{|c|}{ Total } \\
\hline & & & & & & & & & & \\
\hline & $\mathbf{n}$ & $\%$ & $\mathbf{n}$ & $\%$ & $\mathbf{n}$ & $\%$ & $\mathbf{n}$ & $\%$ & $\mathbf{n}$ & $\%$ \\
\hline Kecil: $\leq 4$ orang & 12 & 48 & 14 & 58,3 & 17 & 56,6 & 7 & 33,3 & 50 & 50 \\
\hline Sedang: & 8 & 32 & 7 & 29,2 & 7 & 23,4 & 7 & 33,3 & 29 & 29 \\
\hline orang & 5 & 20 & 3 & 12,5 & 6 & 20 & 7 & 33,3 & 21 & 21 \\
\hline Besar: $\geq 7$ orang & & & & & & & & & & \\
\hline Jumlah & 25 & 100 & 24 & 100 & 30 & 100 & 21 & 100 & 100 & 100 \\
\hline
\end{tabular}

Berdasarkan pengelompokkan tersebut dari 29 persen rumah tangga sedang dan 21 keempat kecamatan setengah (50 persen) persen rumah tangga besar. responden merupakan rumah tangga kecil,

Tabel 8. Sebaran Rumahtangga Berdasarkan Ketahanan Pangan dan Ukuran Rumahtangga

\begin{tabular}{|c|c|c|c|c|c|c|c|c|c|c|}
\hline \multirow[t]{2}{*}{$\begin{array}{l}\text { Kelompok } \\
\text { Umur }\end{array}$} & \multicolumn{2}{|c|}{$\begin{array}{c}\text { Rawan } \\
\text { Pangan } \\
\text { Berat }\end{array}$} & \multicolumn{2}{|c|}{$\begin{array}{l}\text { Rawan } \\
\text { Pangan } \\
\text { Sedang }\end{array}$} & \multicolumn{2}{|c|}{$\begin{array}{l}\text { Rawan } \\
\text { Pangan } \\
\text { Ringan }\end{array}$} & \multicolumn{2}{|c|}{ Tahan Pangan } & \multicolumn{2}{|c|}{ Total } \\
\hline & $\mathbf{n}$ & $\%$ & $\mathbf{n}$ & $\%$ & $\mathbf{n}$ & $\%$ & $\mathbf{n}$ & $\%$ & $\mathbf{n}$ & $\%$ \\
\hline Kecil: $\leq 4$ & 7 & 26.9 & 1 & 20.0 & 4 & 57.1 & 38 & 60.3 & 50 & 49.5 \\
\hline orang & 10 & 38.5 & 4 & 80.0 & 3 & 42.9 & 13 & 20.6 & 30 & 29.7 \\
\hline $\begin{array}{l}\text { Sedang: 5-6 } \\
\text { orang }\end{array}$ & 9 & 34.6 & 0 & 0 & 0 & 0 & 2 & 19.0 & 20 & 20.8 \\
\hline $\begin{array}{l}\text { Besar: } \geq 7 \\
\text { orang } \\
\text { Jumlah }\end{array}$ & 7 & 100.0 & 5 & 100.0 & 26 & 100.0 & 62 & 100.0 & 100 & 100.0 \\
\hline
\end{tabular}

Karakteristik lain untuk mengidentifikasi rumahtangga yang tahan pangan dapat dilihat berdasarkan ukuran rumahtangga. Berdasarkan Tabel 10 maka dapat dilihat bahwa, rumah tangga tahan pangan adalah rumahtangga kecil (60.3 persen) yang terdiri dari 4 orang anggota rumahtangga, sedangkan rumahtangga rawan pangan ringan sebanyak 57.1 persen merupakan rumahtangga kecil dan sisanya 42.9 persen 
adalah rumahtangga sedang.Berdasarkan analisis korelasi Spearman terdapat hubungan negatif $(\mathrm{r}=-0.261, \mathrm{p}<0.01)$ antara ukuran rumahtangga dengan ketahanan pangan rumahtangga. Hasil tersebut menunjukkan bahwa semakin besar ukuran rumahtangga maka semakin kecil peluang tercapainya ketahanan pangan rumahtangga.

Tabel 9. Klasifikasi Kepemilikan Luas Lahan

\section{Kepemilikan Luas Lahan}

Rumahtangga

responden diklasifikasikan menjadi empat golongan berdasarkan kepemilikan lahan, yaitu tidak memiliki lahan, memiliki lahan dibawah $5000 \mathrm{~m}^{2}$, memiliki lahan $5000-10000 \mathrm{~m}^{2}$, dan memiliki lahan lebih dari $10000 \mathrm{~m}^{2}$.

\begin{tabular}{lcccccccccc}
\hline $\begin{array}{c}\text { Luas Lahan } \\
\text { Yang Dimiliki }\end{array}$ & \multicolumn{2}{c}{ Tampan } & \multicolumn{2}{c}{$\begin{array}{c}\text { Marpoyan } \\
\text { Damai }\end{array}$} & \multicolumn{3}{c}{ Rumbai } & \multicolumn{2}{c}{$\begin{array}{c}\text { Rumbai } \\
\text { Pesisir }\end{array}$} \\
& $\mathbf{n}$ & $\%$ & $\mathbf{n}$ & $\%$ & $\mathbf{n}$ & $\%$ & $\mathbf{n}$ & $\%$ & $\mathbf{n}$ & $\%$ \\
\hline 0 & 3 & 27,0 & 9 & 23,2 & 5 & 25 & 5 & 16,6 & 22 & 22 \\
$<5000$ & 4 & 36,4 & 10 & 25,6 & 12 & 6 & 22 & 73,3 & 48 & 48 \\
$5000 \quad 10000$ & 2 & 18,8 & 15 & 38,4 & 2 & 10 & 2 & 6,6 & 21 & 21 \\
$>10000$ & 2 & 18,8 & 5 & 12,8 & 1 & 5 & 1 & 3,3 & 9 & 9 \\
& & & & & & & & & & \\
Jumlah & 11 & 100 & 39 & 100 & 20 & 100 & 30 & 100 & 100 & 100 \\
\hline
\end{tabular}

Berdasarkan penggolongan tersebut dapat dilihat sebaran rumah tangga dari keempat kecamatan memiliki lahan $<5000 \mathrm{~m}^{2}$ di Kecamatan Tampan (36,4 persen), sedangkan di Kecamatan Marpoyan Damai memiliki lahan 5000 - $10000 \mathrm{~m}^{2}$ (38,4 persen).
Sementara di Kecamatan Rumbai dan Rumbai Pesisir 25 dan 16,6 persen respoden tidak memiliki lahan, artinya mereka hanya menyewa atau menerima upah menggarap lahan orang lain.

Tabel 10.Sebaran Rumahtangga Berdasarkan Kepemilikian Luas Lahan dan Ketahanan Pangan.

\begin{tabular}{|c|c|c|c|c|c|c|c|c|c|c|}
\hline \multirow[t]{2}{*}{$\begin{array}{c}\text { Luas Lahan } \\
\text { yang } \\
\text { Dimiliki }\end{array}$} & \multicolumn{2}{|c|}{$\begin{array}{c}\text { Rawan } \\
\text { Pangan } \\
\text { Berat }\end{array}$} & \multicolumn{2}{|c|}{$\begin{array}{l}\text { Rawan } \\
\text { Pangan } \\
\text { Sedang }\end{array}$} & \multicolumn{2}{|c|}{$\begin{array}{l}\text { Rawan } \\
\text { Pangan } \\
\text { Ringan }\end{array}$} & \multicolumn{2}{|c|}{ Tahan Pangan } & \multicolumn{2}{|c|}{ Total } \\
\hline & $\mathbf{n}$ & $\%$ & $\mathbf{n}$ & $\%$ & $\mathbf{n}$ & $\%$ & $\mathbf{n}$ & $\%$ & $\mathbf{n}$ & $\%$ \\
\hline 0 & 2 & 27,0 & 2 & 23,2 & 14 & 60,8 & 17 & 66,7 & 35 & 35 \\
\hline$<5000$ & 1 & 36,4 & 2 & 25,6 & 10 & 17,3 & 23 & 23,3 & 36 & 36 \\
\hline $5000-10000$ & 0 & 18,8 & 1 & 38,4 & 4 & 17,3 & 15 & 6,6 & 20 & 20 \\
\hline
\end{tabular}




\begin{tabular}{lllllllllll}
\hline$>10000$ & 0 & 18,8 & 0 & 12,8 & 1 & 4,3 & 8 & 3,3 & 9 & 9 \\
& & & & & & & & & & \\
Jumlah & 3 & 100 & 5 & 100 & 29 & 100 & 63 & 100 & 100 & 100 \\
\hline
\end{tabular}

Dari gambaran tersebut dapat dilihat bahwa rumah tangga yang tahan pangan sebagian besar adalah rumah tangga yang memiliki lahan garapan, sedangkan rumah tangga rawan pangan berat adalah rumah tangga yang tidak memiliki lahan. Berdasarkan analisis korelasi Spearman diperoleh $\mathrm{r}=$ 0,273 dan $\mathrm{p}<0,01$ antara kepemilikan luas lahan dengan ketahanan pangan rumah tangga. Hasil tersebut menunjukkan bahwa terdapat hubungan positif yang signifikan antara kepemilikan luas lahan dengan ketahanan pangan rumah tangga.Semakin luas lahan yang dimiliki maka semakin besar peluang tercapainya ketahanan pangan rumah tangga.

\section{Keragaman Derajat Ketahanan Pangan Rumah Tangga Perempuan Tani di Kota Pekanbaru}

Derajat ketahanan pangan dilihat dari berbagai aspek, salah satunya adalah indikator derajat pangam yang diklasifikasikan oleh Swindale dan Bilinsky (2007); Smith dan Subandono (2007) yang mengukur derajat ketahanan pangan berdasarkan jumlah bahan pangan atau kelompok pangan yang dikonsumsi oleh rumah tangga. KOnsumsi pangan rumah tangga dibagi dalam 7 kategori, yaitu: (1) biji-bijian, akar-akaran, dan umbi-umbian; (2) kacang-kacangan; (3) produk ternak; (4) daging, ikan dan telur; (5) minyak dan lemak; (6) buah-buahan; dan (7) sayursayuran. Rata-rata kelompok pangan yang dikonsumsi oleh rumah tangga perempuan tani di Kota Pekanbaru adalah 5.64 (Tabel 11).

Di Kota Pekanbaru umumnya kelompok pangan yang tidak dikonsumsi rumah tangga petani adalah produk ternak dan buah-buahan.Mereka beranggapan bahwa kedua jenis makanan tersebut mahal dan pendapatan mereka tidak mencukupi jika digunakan untuk membeli kelompok bahan pangan tersebut, khususnya untuk produk ternak. Sedangkan untuk buahbuahan mereka hanya mengkonsumsi hasil buah-buahan dari pekarangan mereka sendiri

Tabel 11. Derajat Ketahanan Pangan Rumah Tangga Perempuan Tani di Kota Pekanbaru

\begin{tabular}{lc}
\hline \multicolumn{1}{c}{ Ketahanan Pangan } & Hasil \\
\hline Rata-Rata Kelompok Pangan yang Dikonsumsi & 5,64 \\
Derajat ketahanan pangan $(\%)^{1}$ & \\
\hline
\end{tabular}


- $\quad$ Tinggi $(>6)$

- Sedang $(4,5-6)$

10,35

- $\operatorname{Rendah}(<4,5)$

86,21

3,45

- $\operatorname{Rawan}(<5,6)$

- $\operatorname{Sedang}(\geq 5,6)$

40,23

59,77

Sumber : Data Primer (Diolah), 2016

Keterangan:

1) Berdasarkan klasifikasi Swindale and Bilinsky (2005) dalam Smith and Subandoro (2007)

2) Berdasarkan Smith and Subandoro (2007)

Derajat ketahanan pangan rumah tangga perempuan tani di Kota Pekanbaru secara umum tergolong pada kategori sedang 86,21 persen dan hanya 3,45 persen yang termasuk dalam kategori rendah yang berarti mengkonsumsi biji-bijian, akarakaran dan umbi-umbian; kacang-kacangan; minyak dan lemak; serta sayur-sayuran. Berdasarkan data tersebut terlihat bahwa sebagian besar keluarga perempuan tani di Kota Pekanbaru termasuk dalam kategori tahan pangan (59,77 persen) sedangkan yang

Tabel 12. Peran Perempuan Tani dalam Konsumsi Bahan Pangan Pada Tingkat Rumah Tangga di Kota Pekanbaru Tahun 2016

\begin{tabular}{llcc}
\hline No & \multicolumn{1}{c}{ Variabel } & $\begin{array}{c}\text { Koefisien } \\
\text { Regresi }\end{array}$ & t- hitung \\
1 & Pendapatan Rumahtangga & 0,018 & $1,857^{* *}$ \\
2 & Pendapatan Perempuan Tani & 0,064 & $4,489^{* *}$ \\
3 & Pendidikan Perempuan Tani & 1,450 & $6,391^{* *}$ \\
4 & Jumlah Anggota Keluarga & 1,622 & $4,334^{* * *}$ \\
5 & Pengetahuan Gizi Perempuan Tani & 1,457 & $1,889^{* *}$ \\
6 & Umur Perempuan Tani & $-0,195$ & $-0,216^{\mathrm{ns}}$ \\
7 & Konstanta & 21,772 & 10,754 \\
$\mathrm{R}^{2}$ & & \\
0,799 & & & \\
F- hitung & & \\
\hline
\end{tabular}

termasuk rawan pangan berkisar 40,23 persen.

\section{Kapasitas Perempuan Tani Dalam Konsumsi Bahan Pangan Guna Mewujudkan Ketahanan Pangan pada Tingkat Rumah Tangga di Kota Pekanbaru}

Hasil estimasi yang diperoleh menunjukkan bahwa secara bersama-sama variabel pendapatan rumah tangga, pendapatan perempuan tani, pendidikan perempuan tani, jumlah anggota keluarga, umur perempuan tani dan pengetahuan gizi perempuan tani yang merupakan indikator dari peran perempuan berpengaruh terhadap konsumsi pangan yang merupakan indikator dari ketahanan pangan sebesar 0,799, sedangkan sisanya sebesar 0,201 dipengaruhi oleh faktor lain di luar model. 
Sumber: Analisis Data Primer (Diolah), 2016

Keterangan: ${ }^{* * *}=$ Signifikan pada tingkat kepercayaan $99 \%$

** = Signifikan pada tingkat kepercayaan $95 \%$

${ }^{*}=$ Signifikan pada tingkat kepercayaan $90 \%$

Jumlah anggota rumah tangga menunjukkan pengaruh yang signifikan terhadap konsumsi bahan pangan pada tingkat rumah tangga dengan hubungan positif. Artinya kenaikan jumlah anggota keluarga akan meningkatkan secara nyata konsumsi bahan pangan pada tingkat rumah tangga.

Umur perempuan tani menunjukkan pengaruh yang non signifikan terhadap konsumsi bahan pangan rumah tangga.Hal ini menunjukkan bahwa tidak adanya

Tabel 13. Faktor-Faktor Yang Mempengaruhi Pengeluaran Bahan Pangan Pokok Pada Tingkat Rumah Tangga di Kota Pekanbaru Tahun 2016

\begin{tabular}{llcc}
\hline No & \multicolumn{1}{c}{ Variabel } & $\begin{array}{c}\text { Koefisien } \\
\text { Regresi }\end{array}$ & t- hitung \\
\hline 1 & Harga Beras & 0,751 & $1,864^{*}$ \\
2 & Harga Bahan Pangan Lain & $-0,316$ & $-1,479^{\mathrm{ns}}$ \\
3 & Pendapatan Rumah Tangga & 0,199 & $1,625^{\mathrm{ns}}$ \\
4 & Jumlah Anggota Rumah Tangga & 0,543 & $4,220^{* * *}$ \\
5 & Pendidikan Perempuan Tani & 0,162 & $1,719^{*}$ \\
7 & Konstanta & 5,60 & 1,380 \\
$\mathrm{R}^{2}$ & & & \\
0,62 & & \\
F- hitung & & \\
$6,919^{* * *}$ & & \\
\hline
\end{tabular}

Sumber: Analisis Data Primer (Diolah), 2016

Keterangan: ${ }^{* * *}=$ Signifikan pada tingkat kepercayaan $99 \%$

${ }^{* *}=$ Signifikan pada tingkat

kepercayaan $95 \%$

${ }^{*}=$ Signifikan pada tingkat

kepercayaan $90 \%$ memperhatikan keberagaman konsumsi pangan pada tingkat rumah tangga.

Faktor-Faktor yang Mempengaruhi Pengeluaran Bahan Pokok Pada Tingkat Rumah Tangga Perempuan Tani di Kota Pekanbaru

Hasil estimasi yang diperoleh menunjukkan bahwa secara bersama-sama variabel harga beras, harga pangan lain, pendapatan rumah tangga, jumlah anggota rumah tangga dan pendidikan mempengaruhi terhadap pola pengeluaran pokok sebesar 0,62 sedangkan sisanya sebesar $0,38 \%$ dipengaruhi oleh faktor lain di luar model. pengaruh umur perempuan tani untuk
Harga pangan lain dan pendapatan rumah tangga tidak menunjukkan pengaruh yang signifikan terhadap pengeluaran bahan pangan pokok pada tingkat rumah tangga.

\section{Kapasitas Perempuan Tani Dalam Mewujudkan Ketahanan Pangan Untuk}




\section{Menghadapi Era Globalisasi di Kota Pekanbaru}

Krisis ekonomi yang menerpa Indonesia pada 1997-1998 memperlihatkan wajah sesungguhnya dari ketergantungan yang besar pada beras untuk memenuhi kebutuhan pangan. Sumber karbohidrat lain seperti umbi-umbian, jagung dan lain-lain tidak menarik untuk menggantikannya.,
Krisis tersebut memberikan peringatan yang jelas bahwa mengandalkan kebutuhan pangan, khususnya karbohidrat, dari beras menjadi titik rawan dalam membangun ketahanan pangan. Upaya diversifikasi pangan lokal juga perlu diberdayakan pada masyarakat, sehingga permasalahan kelaparan tidak terjadi lagi di Indonesia.

Tabel 14. Diversifikasi Pangan Lokal Oleh Perempuan Tani di Kota Pekanbaru

\begin{tabular}{|c|c|c|c|c|c|c|c|c|c|c|c|c|}
\hline \multirow[t]{2}{*}{$\begin{array}{l}\text { Kelompok } \\
\text { Perempuan }\end{array}$} & \multicolumn{2}{|c|}{$\begin{array}{l}\text { Olahan } \\
\text { Ubi Kayu }\end{array}$} & \multicolumn{2}{|c|}{$\begin{array}{l}\text { Olahan } \\
\text { Jagung }\end{array}$} & \multicolumn{2}{|c|}{$\begin{array}{l}\text { Olahan } \\
\text { Kentang }\end{array}$} & \multicolumn{2}{|c|}{$\begin{array}{c}\text { Olahan } \\
\text { Sagu }\end{array}$} & \multicolumn{2}{|c|}{$\begin{array}{l}\text { Olahan } \\
\text { Pisang }\end{array}$} & \multicolumn{2}{|c|}{ Total } \\
\hline & $\mathbf{n}$ & $\%$ & $\mathbf{n}$ & $\%$ & $\mathbf{n}$ & $\%$ & $\mathbf{n}$ & $\%$ & $\mathbf{n}$ & $\%$ & $\mathbf{n}$ & $\%$ \\
\hline $\begin{array}{c}\text { Perempuan } \\
\text { Tani yang } \\
\text { Mengolah } \\
\text { Pangan }\end{array}$ & 17 & 16.8 & 12 & 11.8 & 0.09 & 2.1 & 0.09 & 2.1 & 16 & 15.8 & 47 & 46,5 \\
\hline $\begin{array}{l}\text { Perempuan } \\
\text { Tani } \\
\text { Yang Tidak } \\
\text { Mengolah } \\
\text { Pangan }\end{array}$ & - & - & - & - & - & - & - & - & - & - & 53 & 53.4 \\
\hline
\end{tabular}

Dari tabel di atas olahan pangan yang sering dibuat oleh perempuan tani adalah olahan ubi kayu (16.8\%), olahan pisang (15.8\%), olahan jagung $(11.8 \%)$ serta olahan kentang dan sagu masing-masing 2.1\%. Keadaan ini diduga terjadi karena sebagian besar responden memilih jenis pangan yang dikonsumsi hanya berdasarkan ketersediaan pangan yang terdapat di wilayahnya dan berdasarkan kebiasan makan.

Terkait dengan keikutsertaan perempuan tani dalam kelembagaan, dari seluruh responden hanya 24 orang $(23.7 \%)$ yang tergabung dalam keanggotaan Kelompok Tani.Namun mereka tidak pernah mendapat pelatihan mengenai manajemen keuangan keluarga untuk mewujudkan ketahanan pangan hingga pendiversifikasian produk olahan pangan untuk menghadapi ancaman globalisasi.

\section{KESIMPULAN}

Kondisi ketahanan pangan di Kota Pekanbaru pada kondisi tahan pangan.

Faktor-faktor yang mempengaruhi kapasitas perempuan tani dalam 
mewujudkan ketahanan pangan tingkat rumah tangga adalah: pendapatan perempuan tani, pendidikan perempuan tani dan pengetahuan gizi perempuan tani.

Faktor-faktor yang mempengaruhi pengeluaran bahan-bahan pangan pada tingkat rumah tangga perempuan tani di Kota Pekanbaru adalah harga beras, pendapatan rumah tangga, jumlah anggota rumah tangga dan tingkat pendidikan.

Kapasitas perempuan tani dalam pengolahan pangan masih rendah, keadaan ini diduga terjadi karena sebagian besar contoh memilih jenis pangan yang dikonsumsi hanya berdasarkan ketersediaan pangan yang terdapat di wilayahnya dan berdasarkan kebiasan makan.

Ancaman globalisasi terhadap ketahanan pangan di Kota Pekanbaru dapat diatasi dengan program pemberdayaan masyarakat tani, yaitu dengan proses peningkatan kemampuan perempuan tani. Dalam memberdayakan petani tidak hanya dengan memproteksi perdagangan beras, tetapi juga mengangkat kehidupan petani melalui program-program yang meningkatkan usaha pertanian lokal.

\section{SARAN}

Mengaktifkan kembali fungsi kelompok perempuan tani termasuk juga PKK khususnya pemberian penyuluhan mengenai manajemen keuangan rumah tangga untuk mewujudkan rumah tangga yang tahan pangan dengan prinsip gizi seimbang.

Revitalisasi kelembagaan bagi perempuan tani seperti kelompok tani perempuan sebagai wadah aspirasi, pusat memperoleh informasi dan pemberdayaan perempuan.Pemberian bantuan kredit dan teknologi pada perempuan tani untuk meningkatkan produktivitas dan pendapatan sehingga pola diversifikasi pangan bisa digalakkan terutama bahan pangan pengganti beras yang berbasis sumberdaya lokal di Kota Pekanbaru untuk menghadapi ancaman globalisasi.

\section{DAFTAR PUSTAKA}

Ariani, Mewa dan Tri Bastuti Purwantini.2005. Analisis Konsumsi Pangan Rumah Tangga Pasca Krisis Ekonomi di Propinsi Jawa Barat. Bogor: Puslitbang Sosial Ekonomi Pertanian.

BBKP. 2003. Peraturan Pemerintah Republik Indonesia Nomor 68 Tahun 2002 tentang Ketahanan Pangan. Departemen Pertanian. Jakarta

Elizabeth, R. 2007. Peran Ganda WanitaTani Dalam Mencapai Ketahanan Pangan Rumah Tangga di Pedesaan. www.puslittan.bogor.net/berkas_PD F/IPTEK/05-rOSSGANDA.pdf.

Diakses pada tanggal 18 Oktober 2016

Hardiansyah. 2007. Review Faktor Determinan Keragaman Konsumsi Pangan. Jurnal Gizi dan Pangan. Juli 2007 2(2): 55 - 74

Hendayana, R dan Yovita AD. 2008. Anatomi Ketahanan Pangan Pada Rumah Tangga Miskin dan 
Implikasinya Terhadap Kebijakan Inovasi

Pertanian.ntb.litbang.deptan.go.id/in d/2006/SP/anatomi ketahanan. Diakses pada tanggal 19 Oktober 2016

Hurlock EB. 1980. Psikologi Perkembangan Suatu Pendekatan Sepanjang Rentang Kehidupan, Edisi Kelima. Jakarta: Erlangga

Nasir. 1988. Metodologu Penelitian. Ghalia Indah. Jakarta

Sajogyo, P.1994. Peranan Wanita dalam Perkembangan Ekonomi. Obor Jakarta
Smith, Lisa C, and Ali S. 2007.Measuring Food Security Using Household Expenditure Surveys. International Food Policy Research Institute, Wshington DC

Sukiyono, et.all. 2008. Status Wanita dan Ketahanan Pangan Rumah Tangga Nelayan dan Petani Padi Di Kabupaten Muko-Muko Provinsi Bengkulu. Jurnal Agro Ekonomi Volume 26 no.2 Oktober 2008: 191 207 